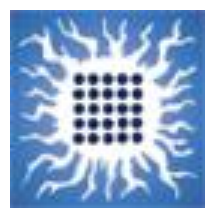

Институт за нуклеарне науке „Винча“

Универзитет у Београду

VINČA Institute of Nuclear Sciences

University of Belgrade

2019

Sorption of divalent heavy metal ions onto functionalized biogenic hydroxyapatite with caffeic acid and 3,4-dihydroxybenzoic acid

\author{
Ivana D. Smičiklas;, Vesna M. Lazić; Ljiljana S. Živković; Slavica J. Porobić; S. Phillip Ahrenkiel; \\ Jovan M. Nedeljković
}

Published in:

Journal of Environmental Science and Health, Part A

DOI:

$\underline{10.1080 / 10934529.2019 .1606575}$

Document version:

Peer reviewed article (often known as postprint article)

Recommended citation:

Smičiklas, Ivana D., Vesna M. Lazić, Ljiljana S. Živković, Slavica J. Porobić, S. Phillip Ahrenkiel, and Jovan M. Nedeljković. "Sorption of divalent heavy metal ions onto functionalized biogenic hydroxyapatite with caffeic acid and 3, 4-dihydroxybenzoic acid." Journal of Environmental Science and Health, Part A (2019): 899-905.

this work is licenced under Creative Commons Attribution-Noncommercial-NoDerivates 4.0

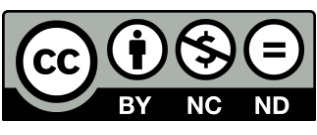


This is an Accepted Manuscript of an article published by Taylor \& Francis in JOURNAL OF

ENVIRONMENTAL SCIENCE AND HEALTH, PART A, 2019, VOL. 54, NO. 9, 899-905, available online: https://doi.org/10.1080/10934529.2019.1606575

\title{
Sorption of divalent heavy metal ions onto functionalized biogenic hydroxyapatite with caffeic acid and 3,4-dihydroxybenzoic acid
}

\author{
IVANA D. SMIČIKLAS ${ }^{1}$, VESNA M. LAZIĆ ${ }^{1}$, LJILJANA S. ŽIVKOVIĆ ${ }^{1}$, SLAVICA J. \\ POROBIĆ ${ }^{1}$, S. PHILLIP AHRENKIEL ${ }^{2}$, and JOVAN M. NEDELJKOVIĆ ${ }^{1}$ \\ ${ }^{1}$ Vinča Institute of Nuclear Sciences, University of Belgrade, P.O. Box 522, 11001 Belgrade, \\ Serbia \\ ${ }^{2}$ South Dakota School of Mines and Technology, 501 E. Saint Joseph Street, Rapid City, SD \\ 57701, USA
}

\begin{abstract}
The sorption ability of biogenic hydroxyapatite (BHAP) towards heavy metal ions $(\mathrm{Pb}, \mathrm{Cu}, \mathrm{Ni}$, $\mathrm{Cd}$, and $\mathrm{Zn}$ ) is compared with functionalized BHAP powders with caffeic acid (CA) and 3,4dihydroxybenzoic acid (3,4-DHBA). The functionalization of the BHAP with either CA or 3,4DHBA is indicated by the appearance of the colored powders due to the formation of the interfacial charge transfer (ICT) complexes. The detailed characterization of as-prepared and functionalized BHAP samples was performed using transmission electron microscopy, reflection spectroscopy, thermogravimetric analysis and determination of zeta potential. All three sorbents
\end{abstract}


clearly displayed preferential sorption of $\mathrm{Pb}$ ions when the total concentration of multicomponent equimolar solutions of heavy metal ions is high. It should be emphasized that the sorption capacity of functionalized BHAP with either CA or 3,4-BHAP was found to be higher, up to $60 \%$, compared to as-prepared $\mathrm{BHAP}$ without the decrease of selectivity towards $\mathrm{Pb}$ ions.

*Address correspondence to Ivana Smičiklas, Vinča Institute of Nuclear Sciences, University of Belgrade, 11001 Belgrade, Serbia; Phone:+381 11 3408574; Fax: +381 11 6308437;

E-mail: ivanat@vin.bg.ac.rs

KEYWORDS: Animal bones, hydroxyapatite, sorption, heavy metal ions, functionalization, catechol derivatives.

\section{Introduction}

Hydroxyapatite $\left(\mathrm{Ca}_{10}\left(\mathrm{PO}_{4}\right)_{6}(\mathrm{OH})_{2}\right.$, HAP) exhibits unique physicochemical properties thanks to which it has a wide range of applications in biomedicine, environmental remediation, materials science, catalysis, chromatography, etc. ${ }^{[1-4]}$ The potential of calcium, phosphate and hydroxyl ions in the crystal lattice of HAP to be replaced with a variety of ions present in surrounding media gave a burst to investigations of the potential use of HAP as a sorbent in separation processes. ${ }^{[5,6]}$ Although the ability to control the physicochemical properties of HAP by choosing synthetic routes and conditions is an advantage in specific fields of research and application, the amounts of material required for the practical utilization of HAP in pollution prevention, water treatment and soil remediation justify the use of naturally available HAP forms (geological, biogenic) over the synthetic ones. 
Compared to geological deposits of phosphate rock, ${ }^{[7]}$ animal bones have gained increased attention as a natural source of HAP due to more favorable properties, i.e., the trace-level concentrations of potentially toxic elements, the nano-size and large specific surface area of biogenic HAP (BHAP) crystals. ${ }^{[8]}$ Besides, phosphate rock is on the European Commission List of critical raw materials, ${ }^{[9]}$ while the biogenic waste is marked as the most important secondary source of phosphorous. ${ }^{[10]}$ Therefore, the transformation of waste animal bones from growing meat industry into the sorbent material is highly encouraged.

In the course of BHAP preparation, organic phase can be removed from bone matrix by chemical treatments (nitric acid, sodium hydroxide, hexane, alcohol, hydrogen peroxide), ${ }^{[11-13]}$ thermal treatments at different annealing temperatures and conditions, ${ }^{[12,14]}$ as well as combining chemical and thermal treatments. ${ }^{[15,16]}$ Isolated BHAP exhibited a larger specific surface area and the reactivity in comparison to the bone composite, which led to enhanced capacities of sorption. ${ }^{[11-15]}$

Further enhancement of the sorption capacity and/or selectivity can be achieved by proper functionalization of HAP with organic molecules, to provide novel surface centers of metal complexation. Although surface modification is widely investigated strategy in HAP biomedical applications (protein separation, drug delivery, cell scaffold, etc.), ${ }^{[17]}$ such approach has rarely been used to modify the performance of HAP in metal separation processes. So far, encouraging results have been reported for amino-functionalized BHAP with salicylate-type of ligand (5aminosalicylic acid) in the separation of $\mathrm{Pb}$ and $\mathrm{Cu}$ ions from contaminated water. ${ }^{[18]}$ Hydroxyapatites with incorporated organic aspartate and glutamate anions have shown increased $\mathrm{Pb}$ sorption capacity in comparison to the untreated sample. ${ }^{[19]}$ Furthermore, organo-apatites prepared by in situ incorporations of adipic acid, citric acid and 
nitrilotris(methylene)triphosphonic acid, with organic content in the $2-8$ wt.- $\%$ range, exhibit faster sorption rate and higher sorption capacity for $\mathrm{Pb}$ in acidic solutions compared to the pure apatite. ${ }^{[20]}$ However, an attempt to improve sorption capacity and selectivity towards heavy metal ions of either synthetic or biogenic HAP by their functionalization with catecholate-type of ligands has never been made. A study of catechol adsorption on HAP was previously performed to evaluate how effective it may be in medical and dental adhesives. ${ }^{[21]}$ It was shown that catechol, and molecules containing catechol groups, have higher rates and energies of adsorption to HAP than alcohols, amines, and carboxylic acids. Recently, the reactivity of HAP-based sorbents for the removal of catechol as a model organic pollutant from an aqueous solution was found promising, with the highest sorption capacity of $15 \mathrm{mg}$ of $\mathrm{C}$ per gram of zinc-doped HAP sorbent. ${ }^{[22]}$

Functionalization of inorganic nanoparticles (mainly wide-band-gap oxides) with small organic molecules (catechol derivatives) so far has been used to prepare inorganic-organic-hybrids with improved optical properties due to the formation of the interfacial charge transfer (ICT) complexes. ${ }^{[23-30]}$ This simple synthetic procedure is based on the condensation reaction between hydroxyl groups from the nanoparticles' surface and adjacent hydroxyl groups from ligand molecules and consequent formation of metal-oxygen-carbon-linkage. Therefore, it can be reasonably assumed that such a reaction will result in modified sorption characteristics of the material.

This study is the continuation of our efforts to improve the sorption ability of biogenic HAP towards heavy metal ions $(\mathrm{Pb}, \mathrm{Cu}, \mathrm{Ni}, \mathrm{Cd}$, and $\mathrm{Zn})$ by proper functionalization. The advantage of the ICT complex formation, based on condensation reaction between surface hydroxyl groups from BHAP and adjacent hydroxyl groups from caffeic acid (CA) and 3,4-dihydroxybenzoic 
acid (3,4-DHBA), was taken to prepare carboxy-functionalized sorbents with carboxylic groups separated at different distances from the surface of the inorganic support. The as-prepared BHAP, as well as functionalized BHAP with CA and 3,4-DHBA, were thoroughly characterized using microscopic and spectroscopic techniques. Effects of surface modification of BHAP on sorption capacity and selectivity were studied in a series of batch experiments using fivecomponent heavy metal mixtures in a wide range of concentrations.

\section{Materials and methods}

\section{Synthesis of BHAP and its functionalization with 3,4-DHBA and CA}

The BHAP was prepared from bovine bones using hydrogen peroxide to remove organic phase, as described elsewhere. ${ }^{[12]}$

The functionalization of BHAP with CA and 3,4-DHBA was performed by dispersing $100 \mathrm{mg}$ of BHAP in $30 \mathrm{~mL}$ of the water solution containing previously dissolved ligand (58.5 and $50 \mathrm{mg}$ of CA and 3,4-DHBA, respectively). The molar concentration of ligands was identical and the ratio between the amount of BHAP and initial concentration of ligands provide the condition for full surface coverage of BHAP. The dispersion was stirred overnight, and, after that, the powder was separated by centrifugation, thoroughly washed four times with deionized water to remove excess ligand, and finally dried in the vacuum oven at $40{ }^{\circ} \mathrm{C}$. The successful surface modification is indicated by coloration of the powder. For the sake of clarity, the functionalized BHAP with CA and 3,4-DHBA will be labeled further in the text as CA/BHAP and 3,4DHBA/BHAP, respectively. 


\section{Characterization of pristine and functionalized $\mathrm{BHAP}$ with 3,4-DHBA and CA}

Microstructural properties of pristine and functionalized BHAP were studied using transmission electron microscopy (TEM). A JEOL JEM-2100 LaB6 instrument operated at $200 \mathrm{kV}$ was used for TEM imaging. TEM images were acquired with a GatanOrius CCD camera at $2 \times$ binning. Specific surface area and the average pore radius of mesoporous BHAP, calculated from the nitrogen adsorption-desorption isotherms according to the BET method, were determined in our previous study ${ }^{[18]}$ and found to be $75.1 \mathrm{~m}^{2} / \mathrm{g}$ and $13.2 \mathrm{~nm}$, respectively.

The content of the organic phase in CA/BHAP and 3,4-DHBA/BHAP samples was determined by thermogravimetric analysis (TGA) using a Setaram Setsys Evolution-1750 instrument. The measurements were performed in the temperature range $25-1000{ }^{\circ} \mathrm{C}$ at a heating rate of 10 ${ }^{\circ} \mathrm{C} / \mathrm{min}$, in the dynamic air atmosphere (flow rate $20 \mathrm{~cm}^{3} / \mathrm{min}$ ).

Optical characterization of as-prepared BHAP, as well as functionalized BHAP with CA and 3,4DHBA, was performed using diffuse reflectance measurements (Shimadzu UV-VIS UV-2600 spectrophotometer equipped with an integrated sphere ISR-2600 Plus).

Electrokinetic properties of BHAP, CA/BHAP, and 3,4-DHBA/BHAP particles were compared using zeta potential analyzer Malvern Zetasizer NanoZS. The dispersion samples $(0.100 \mathrm{~g}$ in $20.00 \mathrm{~mL}$ of $10^{-2} \mathrm{~mol} / \mathrm{L} \mathrm{KNO}_{3}$ ) were equilibrated in PVC vials for $24 \mathrm{~h}$ at room temperature by shaking, and the zeta potential values were recorded at equilibrium $\mathrm{pH}$.

\section{Sorption experiments}


Cation sorption capacity and selectivity of as-prepared BHAP powder were compared with surface-modified BHAP powders with $\mathrm{CA}$ and 3,4-DHBA in a series of equilibrium batch experiments at ambient temperature $\left(21 \pm 2{ }^{0} \mathrm{C}\right)$ by varying the concentration of the equimolar mixture of $\mathrm{Pb}, \mathrm{Cu}, \mathrm{Ni}, \mathrm{Cd}$, and $\mathrm{Zn}$ ions. Five-component water solutions were prepared from nitrate salts of investigated cations to obtain the total concentrations in the range $10^{-3}-10^{-1}$ $\mathrm{mol} / \mathrm{L}$. The initial $\mathrm{pH}$ values of obtained solutions were adjusted to $5.0 \pm 0.2$ by adding minimum amounts of $10^{-2} \mathrm{~mol} / \mathrm{L}$ solutions of either $\mathrm{HNO}_{3}$ or $\mathrm{NaOH}$. The sorbents and solutions were mixed in $50 \mathrm{~mL}$ centrifuge tubes at the constant solid-to-solution ratio $(0.100 \mathrm{~g}$ in $20.00 \mathrm{~mL})$ and shaken for $24 \mathrm{~h}$ on an overhead laboratory shaker at a speed of $10 \mathrm{rpm}$. Purified liquid phases were separated by centrifuging the suspensions at $9000 \mathrm{rpm}$ for 7 minutes using Heraeus Megafuge 16. The equilibrium $\mathrm{pH}$ values were measured by WTW InoLab $\mathrm{pH}$-meter, while the residual metal concentrations were determined using the Perkin Elmer 3100 Atomic Absorption Spectrophotometer (AAS). Sorbed amounts of each metal cation were calculated as the difference between its initial and final concentration.

\section{Results and Discussion}

\section{Physicochemical properties of BHAP, CA/BHAP, and 3,4-DHBA/BHAP}

The TEM data from as-prepared BHAP powders are presented in Figure 1. The TEM at low magnification (Fig. 1A) indicated the presence of agglomerated rod-like particles $((5-10) \times(30-50) \mathrm{nm}$, diameter by length, respectively). The high-resolution TEM imaging revealed that the rod-like BHAP particles are crystalline (Fig. 2B) with resolved (211) lattice 
fringes parallel to the rod axis. Analysis of the selected area electron diffraction (SAED) pattern (Fig. 1C) revealed the presence of the diffraction rings corresponding to (002), (211), (130), (222), (213), and (304) planes from the hexagonal phase of $\mathrm{Ca}_{5}\left(\mathrm{PO}_{4}\right)_{3}(\mathrm{OH})$ (Fig. 1D). Of course, functionalization of BHAP with either CA or 3,4-DHBA did not induce any morphological changes, and for the sake of clarity, those data are omitted.

The functionalization of BHAP with either CA or 3,4-DHBA is accompanied by the appearance of the pale-brown color of powders. The diffuse reflection spectra of unmodified BHAP, CA/BHAP, and 3,4-DHBA/BHAP powders in the wavelength range $300-1100 \mathrm{~nm}$ are shown in Figure 2 (curves a, b, and c, respectively). The as-prepared BHAP has absorption in the UV spectral region at energies higher than $3.35 \mathrm{eV}$. It is well-known that stoichiometric defect-free HAP is non-absorbing material in the visible as well as UV spectral region. ${ }^{[2]}$ However, quantum chemical calculations based on density functional theory by Bystrov et al. ${ }^{[31]}$ indicated that the presence of oxygen vacancy in the phosphate groups would lead to the energy band gap of about $3.45 \mathrm{eV}$. On the other hand, the CA/BHAP and 3,4-DHBA/BHAP samples are visiblelight-responsive (see Fig. 2) with similar absorption properties (absorption onset at $\sim 900 \mathrm{~nm}$, i.e., $\sim 1.4 \mathrm{eV}$ ). The absorption red-shift induced by functionalization of BHAP with CA and 3,4DHBA is a consequence of the ICT complex formation. The similar effect was observed upon surface-modification of BHAP with salicylate-type of ligand (5-aminosalicylic acid). ${ }^{[18,32]}$ Although the optical properties of surface-modified BHAP with CA and 3,4-DHBA is worthy of further investigation, it is not the main focus of this study.

It should be emphasized, based on the TGA results that the content of organic phases in both inorganic-organic hybrids is very small. The TGA curves of pristine and surface-modified BHAP are almost the same indicating that observed optical effects are induced by less than 3 wt.- $\%$ of 
the organic phase (see Supporting Information, Fig. S1). Small changes of the zeta potential upon surface modification of BHAP with either CA or 3,4-DHBA/BHAP (see Supporting Information, Table S1) are in accordance with the low content of organic phase determined by TGA measurements. It is worth noting that in the inert electrolyte at equilibrium $\mathrm{pH}$ value all samples have negative surface charge $(-10.3,-10.5$, and $-12.3 \mathrm{meV}$ for BHAP, CA/BHAP, and 3,4-DHBA/BHAP, respectively) favorable for sorption of cationic species.

Due to the low concentration of organic components in CA/BHAP and 3,4-DHBA/BHAP samples, our attempt to confirm the mode of coordination between ligand molecules and BHAP using FTIR spectroscopy failed. Simply, complete disappearance of all vibration bands that belong to CA and 3,4-DHBA was observed upon their chemisorption onto BHAP powder. However, extensive literature data concerning the ICT complexes between various wide-bandgap oxides such as $\mathrm{TiO}_{2}{ }^{[23-27]}$ and $\mathrm{Al}_{2} \mathrm{O}_{3}{ }^{[29,30]}$ and variety of catecholate-type of ligands strongly suggest that the ICT complex between BHAP and CA as well as BHAP and 3,4-DHBA is facilitated by the condensation reaction between surface hydroxyl groups from BHAP and adjacent hydroxyl groups from ligand molecules. To conclude, functionalization of BHAP with CA and 3,4-DHBA provide two sorbents with the same free functional group - carboxylic placed at the different distances from the surface of the inorganic support.

\section{Sorption properties of $B H A P, C A / B H A P$, and 3,4-DHBA/BHAP}

The total sorption capacities of as-prepared and functionalized BHAP (CA/BHAP and 3,4DHBA/BHAP) powders exposed to equimolar $\mathrm{Pb}, \mathrm{Cu}, \mathrm{Ni}, \mathrm{Cd}$, and $\mathrm{Zn}$ solutions, as well as corresponding equilibrium $\mathrm{pH}$ values are shown in Figure 3. Based on the sorption data, some 
general features can be readily recognized. First, the total molar amounts of cations sorbed by BHAP, CA/BHAP, and 3,4-DHBA/BHAP from equimolar five-component solutions increases with the increase of the initial concentration of heavy metal ions, and the saturation is reached at high metal loadings. Second, the sorption capacities of as-prepared and functionalized BHAP powders towards heavy metal ions are similar at the low concentration end. However, when the concentration of heavy metal ions is sufficiently high, the enhanced sorption by CA/BHAP and 3,4-DHBA/BHAP can be noticed compared to as-prepared BHAP powder. For example, the total sorption capacity of 3,4-DHBA/BHAP is $60 \%$ higher compared to as-prepared BHAP for the highest initial concentration of heavy metal ions $\left(10^{-1} \mathrm{~mol} / \mathrm{L}\right)$. Third, the increase in metal sorption is accompanied by the decrease in equilibrium $\mathrm{pH}$, and the enhancement of the sorption capacity of functionalized BHAP coincides with the low equilibrium $\mathrm{pH}$ values of multicomponent solutions $(\mathrm{pH} \leq 3.5)$. The lowering of $\mathrm{pH}$ is a consequence of cation sorption via complexation with protonated surface groups of both inorganic and organic components of the hybrid sorbents. ${ }^{[18,33]}$

In multi-component systems, sorption is influenced by the competition of the metal ions for the active surface sites. To evaluate the selectivity of as-prepared BHAP and functionalized BHAP with $\mathrm{CA}$ and 3,4-DHBA, the percentage of sorbed ions $(\mathrm{Pb}, \mathrm{Cu}, \mathrm{Ni}, \mathrm{Cd}$, and $\mathrm{Zn})$ for the lowest and the highest total concentration of equimolar multi-component mixtures $\left(10^{-3}\right.$ and $10^{-1} \mathrm{~mol} / \mathrm{L}$, respectively) is presented in Figure 4. As expected, all three sorbents do not display selectivity when the total concentration of ions is low $\left(10^{-3} \mathrm{~mol} / \mathrm{L}\right)$ due to the presence of the excess of available surface sites. However, when the total concentration of divalent metal ions is high $\left(10^{-1}\right.$ mol/L) - higher than the number of available surface sites - all three sorbents display the selective sorption of $\mathrm{Pb}$ ions. The selective sorption of $\mathrm{Pb}$ ions by $\mathrm{BHAP}$ is in agreement with 
literature data indicating that among divalent metal ions sorption of $\mathrm{Pb}$ is the most efficient due to its preferential removal by dissolution of HAP phase and precipitation of less soluble hydroxypyromorphite. ${ }^{[5,6]}$ Quite the opposite, the maximum sorption capacity for $\mathrm{Pb}$ was the lowest with respect to $\mathrm{Zn}, \mathrm{Cu}, \mathrm{Cd}, \mathrm{Ni}$, and $\mathrm{Co}$ when non-apatite phosphate sorbent was used. ${ }^{[34]}$ It should be emphasized that the higher sorption capacity of functionalized BHAP samples did not diminish their selectivity towards the $\mathrm{Pb}$ ions (Fig. 4B). In fact, stability constants measured for the formation of 1:1 complexes between divalent metal ions and different carboxylate anions, including benzoic acid, follow the order $\mathrm{Pb}^{2+}>\mathrm{Cu}^{2+}>\mathrm{Cd}^{2+}>\mathrm{Zn}^{2+}>\mathrm{Ni}^{2+},{ }^{[35]}$ which coincides with the selectivity of modified BHAP samples. The similar preference of $\mathrm{Pb}$ sorption was observed for amino-functionalized BHAP in equilibrium experiments with bi-component solutions of $\mathrm{Pb}$ and $\mathrm{Cu}$ ions. ${ }^{[18]}$

The isotherms of sorption of each component from equimolar five-component solutions $(\mathrm{Pb}, \mathrm{Cu}$, $\mathrm{Ni}, \mathrm{Cd}$, and $\mathrm{Zn}$ ions) by BHAP, CA/BHAP, and 3,4-DHBA/BHAP are shown in Figure 5 (A, B, and $\mathrm{C}$, respectively). It is clear that sorption of $\mathrm{Pb}$ ions by as-prepared $\mathrm{BHAP}$, as well as functionalized BHAP with either CA or 3,4-DHBA, is significantly more pronounced compared to all other investigated ions. Except for $\mathrm{Pb}$, the sorption patterns of studied ions by all three sorbents exhibit a maximum followed by declining or irregular shape of isotherms with the increase of $\mathrm{C}_{\mathrm{e}}$. Such forms of isotherms are generally associated with sorption of less competitive species from the mixture. ${ }^{[18,36]}$ Namely, as long as the active surface sights are not completely saturated, sorption of $\mathrm{Cu}, \mathrm{Ni}, \mathrm{Cd}$, and $\mathrm{Zn}$ ions is not suppressed by the sorption of $\mathrm{Pb}$ ions, but, at high initial concentrations of the mixture, a residual amount of $\mathrm{Pb}$ ions in solution inhibits their further sorption. There is also a competition between the other cations so that $\mathrm{Cu}$ 
and $\mathrm{Cd}$ sorption is still measurable while $\mathrm{Ni}$ and $\mathrm{Zn}$ removal is negligible at higher concentrations of the mixture.

Obviously, the obtained data for sorption of $\mathrm{Cu}, \mathrm{Ni}, \mathrm{Cd}$, and $\mathrm{Zn}$ ions, due to irregular $\mathrm{Q}_{\mathrm{e}}$ versus $\mathrm{C}_{\mathrm{e}}$ dependence, could not be fitted to any isotherm with acceptable correlation coefficients. The sorption patterns of $\mathrm{Pb}$ ions were fitted by Langmuir ${ }^{[37]}$ and Freundlich ${ }^{[38]}$ isotherm models (Equations 1 and 2):

$C_{e} / Q_{e}=1 /\left(Q_{\max } K_{L}\right)+C_{e} / Q_{\max }$

$\log Q_{e}=\log K+1 / n \log C_{e}$

where $Q_{e}(\mathrm{mmol} / \mathrm{g})$ and $C_{e}(\mathrm{mmol} / \mathrm{L})$ represent the equilibrium concentration of $\mathrm{Pb}$ ions in the solid and in the liquid phase, respectively, $Q_{\max }(\mathrm{mmol} / \mathrm{g})$ is the maximum sorption capacity, $K_{L}$ $(\mathrm{L} / \mathrm{mmol})$ represents the Langmuir sorption constant, whereas $K\left(\mathrm{mmol}^{1-1 / \mathrm{n}} \mathrm{L}^{1 / \mathrm{n}} \mathrm{g}^{-1}\right)$ and $1 / n$ are the Freundlich model parameters related to the sorption capacity and affinity. From the linear fits (see Supporting Information, Fig. S3), sorption parameters are calculated and summarized in Table 1.

Based on the obtained correlation coefficients, the isotherms of competitive $\mathrm{Pb}$ sorption generally fit better to the Langmuir than to the Freundlich model. The best correspondence to the Langmuir model has the sorption pattern of $\mathrm{Pb}$ ions by $\mathrm{BHAP}$ with a distinct plateau for high $\mathrm{C}_{\mathrm{e}}$ values. Since Langmuir equation is based on the assumptions that sorption takes place on a homogeneous surface with formation of a monolayer, poorer correlation, obtained for the inorganic-organic hybrid samples may be an indication of $\mathrm{Pb}$ co-sorption by BHAP itself and the organic phase. At the same time, compared to BHAP, surface modified samples exhibit better correlation with Freundlich isotherm typical for sorbents having different active surface sites. Langmuir constant $K_{L}$ decreases in the sequence: BHAP, CA/BHAP, 3,4-DHBA/BHAP, 
indicating that modified samples have a higher capacity but lower affinity for $\mathrm{Pb}$ than the pure BHAP. The shape of cation sorption isotherms on various apatite-based composites was found to be complex, demonstrating that there are different functional groups on the surface which can take action as sorption sites. ${ }^{[39,40]}$

It is well-known that HAP samples of different origin or heaving different treatment history exhibit different selectivity. For example, similar to the results presented in this study, the preferential sorption of $\mathrm{Pb}$ ions has been reported by functionalized BHAP, ${ }^{[18]}$ as well as multiwalled carbon nanotubes, ${ }^{[41]}$ with 5 -aminosalicylic acid. On the other hand, higher sorption capacities were reported for $\mathrm{Cu}$ with respect to $\mathrm{Pb}$ ions using sorbents produced by pyrolysis of cow bones. ${ }^{[42]}$ Also, the strong inhibitory effect of $\mathrm{Cu}$ ions on $\mathrm{Pb}$ sorption by HAP was reported by Ma et al. ${ }^{[43]}$ To briefly conclude, preferential sorption of $\mathrm{Pb}$ ions from the multi-component solutions indicates that BHAP might have potential use as a sorbent for selective removal of $\mathrm{Pb}$ ions from multi-component heavy-metal ions solutions. In addition, functionalization of BHAP with a small amount of adequately chosen ligands (CA and 3,4-DHBA) lead to significant increase of its sorption capacity (up to 60\%), but, does not influence on its selectivity towards $\mathrm{Pb}$ ions.

\section{Conclusion}

The functionalization of BHAP with catecholate-type of ligands (CA and 3,4-DHBA) lead to the formation of inorganic-organic hybrid materials with potential diverse applications including sorption, drug delivery, photo-driven catalytic reactions, etc. The main advantages of the proposed functionalization approach are simplicity and the formation of strong covalent bonds 
between inorganic and organic part of hybrids. The sorption data indicate selective removal of $\mathrm{Pb}$ ions from five-component equimolar solutions of heavy metal ions $(\mathrm{Pb}, \mathrm{Cu}, \mathrm{Ni}, \mathrm{Cd}$, and $\mathrm{Zn}$ ions) by all three sorbents (BHAP, CA/BHAP, and 3,4-DHBA/BHAP). However, the sorption capacities of functionalized BHAP are higher compared to the unmodified one. It should be noted that the better sorption capacity was found for a hybrid sample where the free carboxylic group is closer to the surface of BHAP (3,4-DHBA/BHAP). Simply speaking, functionalization of BHAP with CA and 3,4-DHBA transformed the waste material into sorbent with improved capability for selective removal of heavy metal ions. The increase of the maximum sorption capacity up to $60 \%$, observed for 3,4-DHBA/BHAP compared to unmodified BHAP, cannot be explained from the mechanistic point of view by the presence of organic phase solely. The content of the organic phase is too small. We can only assume that when the concentration of cations is higher than the number of available BHAP surface sites, there is a switch in the sorption mechanism in functionalized BHAP samples. Based on these preliminary results, it seems that systematic investigation of sorption ability of functionalized hydroxyapatite with a variety of multifunctional ligands is worthy of further study.

\section{Acknowledgments}

Financial support for this study is granted by the Ministry of Education, Science and Technological Development of the Republic of Serbia (Projects 45020 and 43009).

\section{References}


[1] Haider, A.; Haider, S.; Han, S.S.; Kang, I.K. Recent advances in the synthesis, functionalization and biomedical applications of hydroxyapatite: a review. RSC Adv. 2017, 7, $7442-7458$.

[2] Piccirillo, C.; Castro, P.M.L. Calcium hydroxyapatite-based photocatalysts for environment remediation: characteristics, performances and future perspectives. J. Environ. Manage. 2017, 193, 79-91.

[3] Dinglin, Z.; Huawen, Z.; Xianying, Z.; Yimin, L.; Hua, C.; Xianjun, L. Application of hydroxyapatite as catalyst and catalyst carrier. Prog. Chem. 2011, 23(4), 687-694.

[4] Cummings, L.J.; Snyder, M.A.; Brisack, K. Protein chromatography on hydroxyapatite columns. Method Enzymol. 2009, 463, 387-404.

[5] Monteil-Rivera, F.; Fedoroff, M. Sorption of inorganic species on apatites from aqueous solutions. Encyclopedia of Surface \& Colloid Science, 2002, 1-26.

[6] Narasaraju, T.S.B.; Phebe, D.E. Some physico-chemical aspects of hydroxylapatite. J. Mater. Sci. 1996, 31(1), 1-21.

[7] Manning, D.A.C. Phosphate minerals, environmental pollution and sustainable agriculture, Elements, 2008, 4(2), 105-108.

[8] Wopenka, B.; Pasteris, J.D. A mineralogical perspective on the apatite in bone. Mat. Sci. Eng. C, 2005, 25(2), 131-143.

[9] European Commission Report on critical raw materials and the circular economy http://ec.europa.eu/docsroom/documents/27348. Accessed 20 January 2019.

[10] Schoumans, O.F.; Bouraoui, F.; Kabbe, C.; Oenema, O.; van Dijk, K.C. Phosphorus management in Europe in a changing world. Ambio, 2015, 44, Suppl 2, S180-S192. 
[11] Kizilkaya, B.; Tekinay, A.A.; Dilgin, Y. Adsorption and removal of $\mathrm{Cu}(\mathrm{II})$ ions from aqueous solution using pretreated fish bones. Desalination, 2010, 264(1-2), 37-47.

[12] Dimović, S.; Smičiklas, I.; Plećaš, I.; Antonović, D.; Mitrić, M. Comparative study of differently treated animal bones for $\mathrm{Co}^{2+}$ removal. J. Hazard. Mater. 2009, 164(1), 279-287.

[13] Park, Y.; Shin, W.S.; Choi, S.J. Removal of cobalt and strontium from groundwater by sorption onto fishbone. J. Radioanal. Nucl. Chem. 2013, 295(1), 789-799.

[14] Chatterjee, S.; Jha, S.; De, S. Novel carbonized bone meal for defluoridation of groundwater: Batch and column study. J. Environ. Sci. Health A, 2018, 53(9), 832-846.

[15] Šljivić-Ivanović, M.; Smičiklas, I.; Milenković, A.; Dojčinović, B.; Babić, B.; Mitrić, M. Evaluation of the effects of treatment factors on the properties of bio-apatite materials. J. Mater. Sci. 2015, 50(1), 354-365.

[16] Ghanei, R.; Dermani, K.; R., Salehi, Y.; Mohammadi, M. Waste animal bone as support for $\mathrm{CaO}$ impregnation in catalytic biodiesel production from vegetable oil. Waste Biomass Valor. 2016, 7(3), $527-532$.

[17] Songbo, N.; Yanbao, L.; Xiumei, W. Preparation, application and functionalization of hydroxyapatite microspheres. Prog. Chem. 2011, 23(1), 231-245.

[18] Smičiklas, I.; Papan, J.; Lazić, V.; Lončarević, D.; Ahrenkiel, S.P.; Nedeljković, J.M. Functionalized biogenic hydroxyapatite with 5-aminosalicylic acid - Sorbent for efficient separation of $\mathrm{Pb}^{2+}$ and $\mathrm{Cu}^{2+}$ ions. J. Environ. Chem. Eng. 2017, 5(4), 3759-3765.

[19] Bachoua, H.; Renaudin, G.; Badraoui, B.; Leroux, F.; Debbabi, M.; Nedele J.M. Preparation and characterization of functionalized hybrid hydroxyapatite from phosphorite and its potential application to $\mathrm{Pb}^{2+}$ remediation. J. Solgel Sci. Technol. 2016, 78(3), 621-631. 
[20] Saoiabi, S.; Achelhi, K.; Masse, S.; Soiabi, A.; Laghzizil, A.; Coradin, T. Organo-apatites for lead removal from aqueous solutions: a comparison between carboxylic acid and aminophosphonate surface modification. Colloids Surf. A, 2013, 419, 180-185.

[21] Chirdon, W.M.; O’Brien, W.J.; Robertson, R.E. Adsorption of catechol and comparative solutes on hydroxyapatite. J. Biomed. Mater. Res. 2003, 66(2), 532-538.

[22] Sebei, H.; Minh, D.P.; Lyczko, N.; Sharrock, P.; Nzihou A. Hydroxyapatite-based sorbents: Elaboration, characterization and application for the removal of catechol from the aqueous phase. Environ. Technol. 2017, 38(20), 2611-2620.

[23] Savić, T.D.; Janković, I.A.; Šaponjić, Z.V.; Čomor, M.I.; Veljković, D.Ž.; Zarić, S.D.; Nedeljković, J.M. Surface modification of anatase nanoparticles with fused catecholate type ligands: a combined DFT and experimental study of optical properties. Nanoscale, 2012, 4(5), 1612-1619.

[24] Milićević, B.; Đorđević, V.; Lončarević, D.; Ahrenkiel, S.P.; Dramićanin, M.D.; Nedeljković, J.M. Visible light absorption of surface modified $\mathrm{TiO}_{2}$ powders with bidentate benzene derivatives. Micropor. Mesopor. Mat. 2015, 217, 184-189.

[25] Higashimoto, S.; Nishi, T.; Yasukawa, M.; Azuma, M.; Sakata, Y.; Kobayashi, H. Photocatalysis of titanium dioxide modified by catechol-type interfacial surface complexes (ISC) with substitued groups. J. Catal. 2015, 329, 286-290.

[26] Zhang, T.; Wojtal, P.; Rubel, O.; Zhitomirsky, I. Density functional theory and experimental studies of caffeic acid adsorption on zinc oxide and titanium dioxide nanoparticles. RSC Adv. 2015, 5(129), 106877-106885. 
[27] Vukoje, I.; Kovač, T.; Džunuzović, J.; Džunuzović, E.; Lončarević, D.; Ahrenkiel, S.P.; Nedeljković, J.M. Photocatalytic ability of visible-light-responsive $\mathrm{TiO}_{2}$ nanoparticles. J. Phys. Chem. C, 2016, 120(33), 18560-18569.

[28] Medić, M.M.; Vasić, M.; Zarubica, A.R.; Trandafilović, L.V.; Dražić, G.; Dramićanin, M.D.; Nedeljković, J.M. Enhanced photoredox chemistry in surface-modified $\mathrm{Mg}_{2} \mathrm{TiO}_{4}$ nano-powders with bidentate benzene derivatives. RSC Adv. 2016, 6(97), 94780-94786.

[29] Đordević, V.; Dostanić, J.; Lončarević, D.; Ahrenkiel, S.P.; Sredojević, D.N.; Švrakić, N.; Belić, M.; Nedeljković, J.M. Hybrid visible-light responsive $\mathrm{Al}_{2} \mathrm{O}_{3}$ particles. Chem. Phys. Lett. 2017, 685, 416-421.

[30] Đorđević, V.; Sredojević, D.N.; Dostanić, J.; Lončarević, D.; Ahrenkiel, S.P.; Švrakić, N.; Brothers, E.; Belić, M.; Nedeljković, J.M. Visible light absorption of surface-modified $\mathrm{Al}_{2} \mathrm{O}_{3}$ powders: A comparative DFT and experimental study. Micropor. Mesopor. Mat. 2019, 273, 41-49.

[31] Bystrov, V.S.; Piccirillo, C.; Tobaldi, D.M.; Castro, P.M.L.; Coutinho, J.; Kopyl, S.; Pullar, R.C. Oxygen vacancies, the optical band gap (Eg) and photocatalysis of hydroxyapatite: comparing modelling with measured data. Appl. Catal. B-Environ. 2016, 196, 100-107.

[32] Lazić, V.; Smičiklas, I.; Marković, J.; Lončarević, D.; Dostanić, J.; Ahrenkiel, S.P.; Nedeljković, J.M. Antibacterial ability of supported silver nanoparticles by functionalized hydroxyapatite with 5-aminosalicylic acid. Vacuum, 2018, 148, 62-68.

[33] Cao, X.; Ma, L.Q.; Rhue, D.R.; Appel, C.S. Mechanisms of lead, copper, and zinc retention by phosphate rock. Environ. Pollut. 2004, 131(3), 435-444. 
[34] Ivanets, A.I.; Srivastava, V.; Kitikova, N.V.; Shashkova, I.L.; Sillanpää, M. Non-apatite CaMg phosphate sorbent for removal of toxic metal ions from aqueous solutions, J. Environ. Chem. Eng. 2017, 5(2), 2010-2017.

[35] Bunting, J.W.; Thong, K.E. Stability constants for some 1:1 metal-carboxylate complexes, Can. J. Chem. 1970, 48(11), 1654-1656.

[36] Cerqueira, B.; Arenas-Lago, D.; Andrade, M.L.; Vega, F.A. Validation of TOF-SIMS and FE-SEM/EDS techniques combined with sorption and desorption experiments to check competitive and individual $\mathrm{Pb}^{2+}$ and $\mathrm{Cd}^{2+}$ association with components of $\mathrm{B}$ soil horizons. PLoS ONE, 2015, 10(4), e0123977.

[37] Langmuir, I. The adsorption of gases on plane surfaces of glass, mica and platinum. J. Am. Chem. Soc. 1918, 40(9), 1361-1403.

[38] Freundlich, H.M.F. Over the adsorption in solution. J. Phys. Chem. 1906, 57, 385-471. [39] Hokkanen, S.; Bhatnagar, A.; Srivastava, V.; Suorsa, V.; Sillanpää, M. Removal of $\mathrm{Cd}^{2+}$, $\mathrm{Ni}^{2+}$ and $\mathrm{PO}_{4}{ }^{3-}$ from aqueous solution by hydroxyapatite-bentonite clay-nanocellulose composite. Int. J. Biol. Macromol. 2018, 118, 903-912.

[40] Hokkanen, S.; Repo, E.; Westholm, L.J.; Lou, S.; Sainio, T.; Sillanpää, M. Adsorption of $\mathrm{Ni}^{2+}, \mathrm{Cd}^{2+}, \mathrm{PO}_{4}{ }^{3-}$ and $\mathrm{NO}_{3}{ }^{-}$from aqueous solutions by nanostructured microfibrillated cellulose modified with carbonated hydroxyapatite. Chem. Eng. J. 2014, 252, 64-74.

[41] Soliman, E.M.; Marwani, H.M.; Albishri, H.M. Novel solid-phase extractor based on functionalization of multi-walled carbon nano tubes with 5-aminosalicylic acid for preconcentration of $\mathrm{Pb}(\mathrm{II})$ in water samples prior to determination by ICP-OES. Environ. Monit. Assess. 2013, 185(12), 10269-10280. 
[42] Moreno-Piraján, J.C.; Gómez-Cruz, R.; García-Cuello, V.S.; Giraldo, L. Binary system $\mathrm{Cu}(\mathrm{II}) / \mathrm{Pb}$ (II) adsorption on activated carbon obtained by pyrolysis of cow bone study. J. Anal. Appl. Pyrol. 2010, 89(1), 122-128.

[43] Ma, Q.Y.; Traina, S.J.; Logan, T.J.; Ryan, J.A. Effects of aqueous Al, Cd, Cu, Fe(II), Ni, and $\mathrm{Zn}$ on Pb immobilization by hydroxyapatite. Environ. Sci. Technol. 1994, 28(7), 12191228. 


\section{FIGURE CAPTIONS}

Figure 1. TEM data from BHAP: (A) TEM image at low magnification, (B) high-resolution lattice image, (C) the SAED pattern (D) with corresponding planes from the hexagonal phase of $\mathrm{Ca}_{5}\left(\mathrm{PO}_{4}\right)_{3}(\mathrm{OH})$

Figure 2. Reflection spectra of BHAP (a), CA/BHAP (b), and 3,4-DHBA/BHAP (c) in UVVis-NIR spectral range

Figure 3. The total sorption capacities of BHAP, CA/BHAP and 3,4-DHBA/BHAP powders exposed to equimolar $\mathrm{Cu}, \mathrm{Pb}, \mathrm{Ni}, \mathrm{Cd}$, and $\mathrm{Zn}$ solutions and the corresponding equilibrium $\mathrm{pH}$ values, in relation to the total initial concentrations

Figure 4. The percentage of sorbed $\mathrm{Cu}, \mathrm{Pb}, \mathrm{Ni}, \mathrm{Cd}$ and $\mathrm{Zn}$ ions from equimolar ion mixtures of total concentration (A) $10^{-3} \mathrm{~mol} / \mathrm{L}$ and (B) $10^{-1} \mathrm{~mol} / \mathrm{L}$, at equilibrium with either BHAP or CA/BHAP or 3,4-DHBA/BHAP powders

Figure 5. The isotherms of sorption of each component from equimolar five-component solutions ( $\mathrm{Cu}, \mathrm{Pb}, \mathrm{Ni}, \mathrm{Cd}$, and $\mathrm{Zn}$ ions) in various systems: (A) BHAP, (B) CA/BHAP, and (C) 3,4-DHBA/BHAP 
Table 1. The parameters of $\mathrm{Pb}^{2+}$ equilibrium sorption from five-component equimolar mixtures calculated by Langmuir and Freundlich isotherm models

\begin{tabular}{|c|c|c|c|c|c|c|c|}
\hline \multirow[b]{2}{*}{ Sample } & \multirow[b]{2}{*}{$\begin{array}{l}Q_{\max , \exp } \\
(\mathrm{mmol} / \mathrm{g})\end{array}$} & \multicolumn{3}{|c|}{ Langmuir model } & \multicolumn{3}{|c|}{ Freundlich model } \\
\hline & & $\begin{array}{c}Q_{\max } \\
(\mathrm{mmol} / \mathrm{g})\end{array}$ & $\begin{array}{c}K_{L} \\
(\mathrm{~L} / \mathrm{mmol})\end{array}$ & $R^{2}$ & $\begin{array}{c}K \\
\left(\mathrm{mmol}^{1-1 / \mathrm{n}} \mathrm{L}^{1 / \mathrm{n}} \mathrm{g}^{-1}\right)\end{array}$ & $1 / n$ & $R^{2}$ \\
\hline BHAP & 1.45 & 1.48 & 1.81 & 0.992 & 0.785 & 0.429 & 0.878 \\
\hline CA/BHAP & 1.97 & 2.10 & 0.84 & 0.991 & 0.795 & 0.596 & 0.936 \\
\hline 3,4-DHBA/BHAP & 2.36 & 2.70 & 0.50 & 0.972 & 0.979 & 0.680 & 0.930 \\
\hline
\end{tabular}




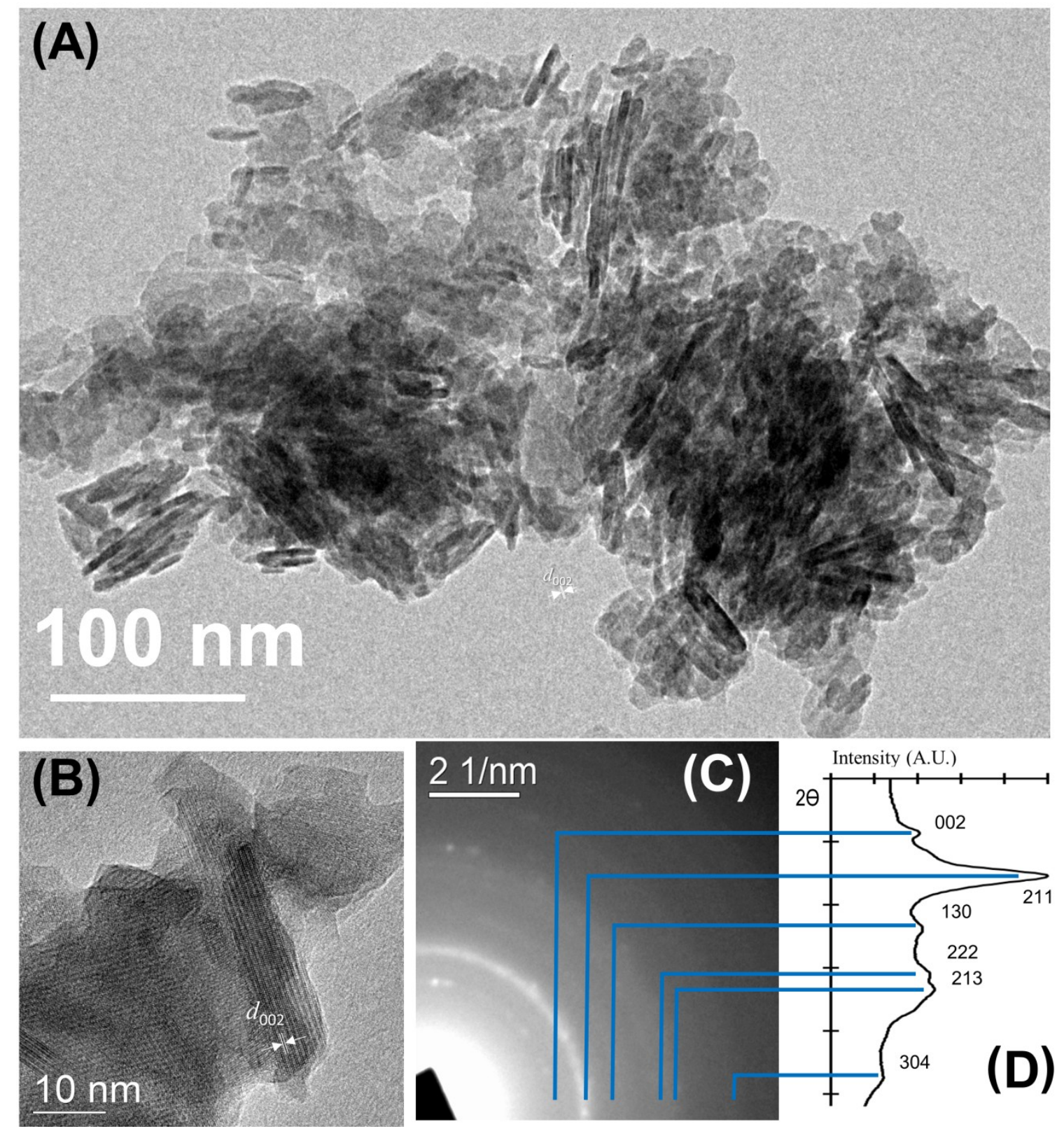

Figure 1. TEM data from BHAP: (A) TEM image at low magnification, (B) high-resolution lattice image, $(\mathrm{C})$ the SAED pattern (D) with corresponding planes from the hexagonal phase of $\mathrm{Ca}_{5}\left(\mathrm{PO}_{4}\right)_{3}(\mathrm{OH})$ 


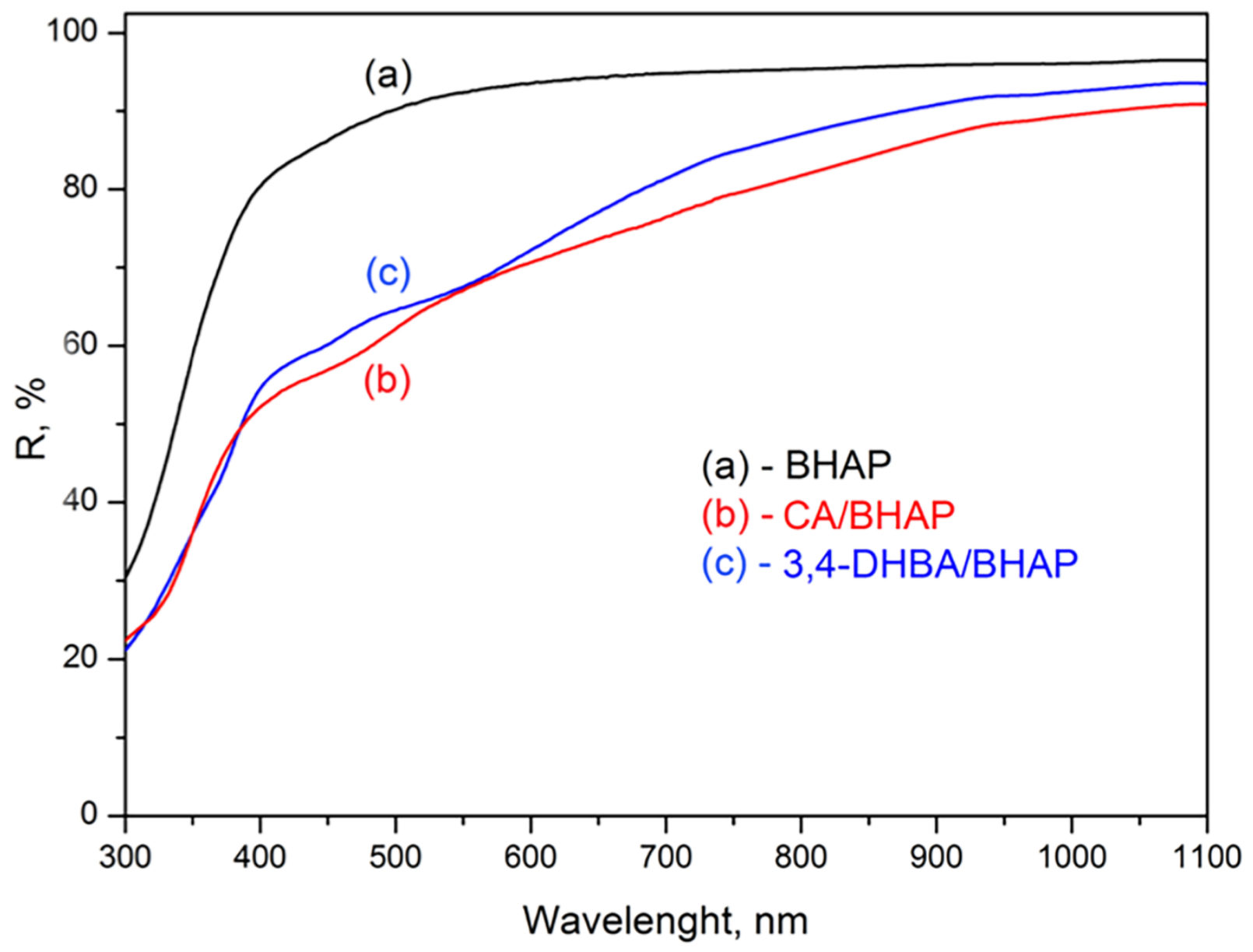

Figure 2. Reflection spectra of BHAP (a), CA/BHAP (b), and 3,4-DHBA/BHAP (c) in UVVis-NIR spectral range 




Figure 3. The total sorption capacities of BHAP, CA/BHAP and 3,4-DHBA/BHAP powders exposed to equimolar $\mathrm{Cu}, \mathrm{Pb}, \mathrm{Ni}, \mathrm{Cd}$, and $\mathrm{Zn}$ solutions and the corresponding equilibrium $\mathrm{pH}$ values, in relation to the total initial concentrations 


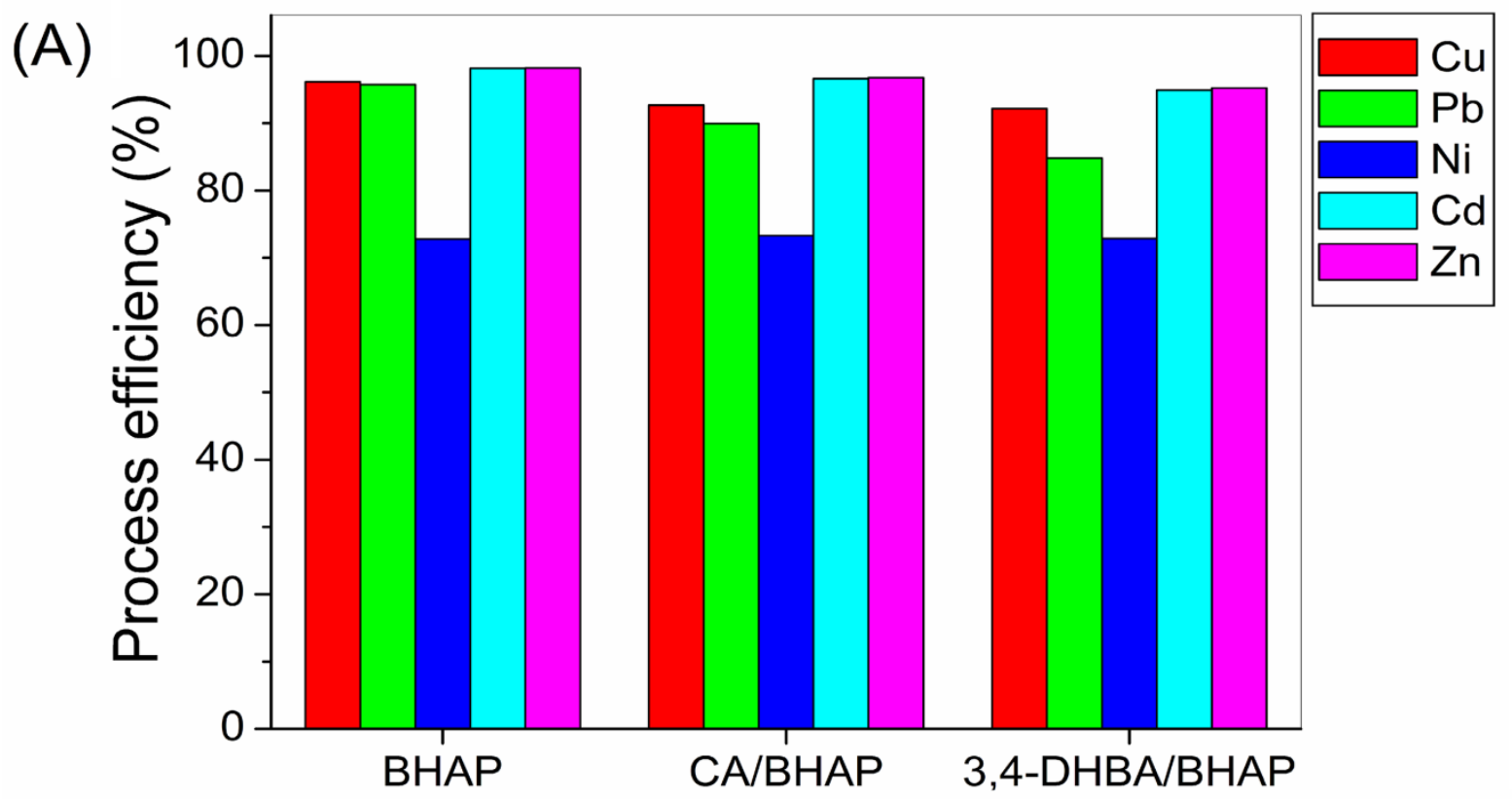

(B)

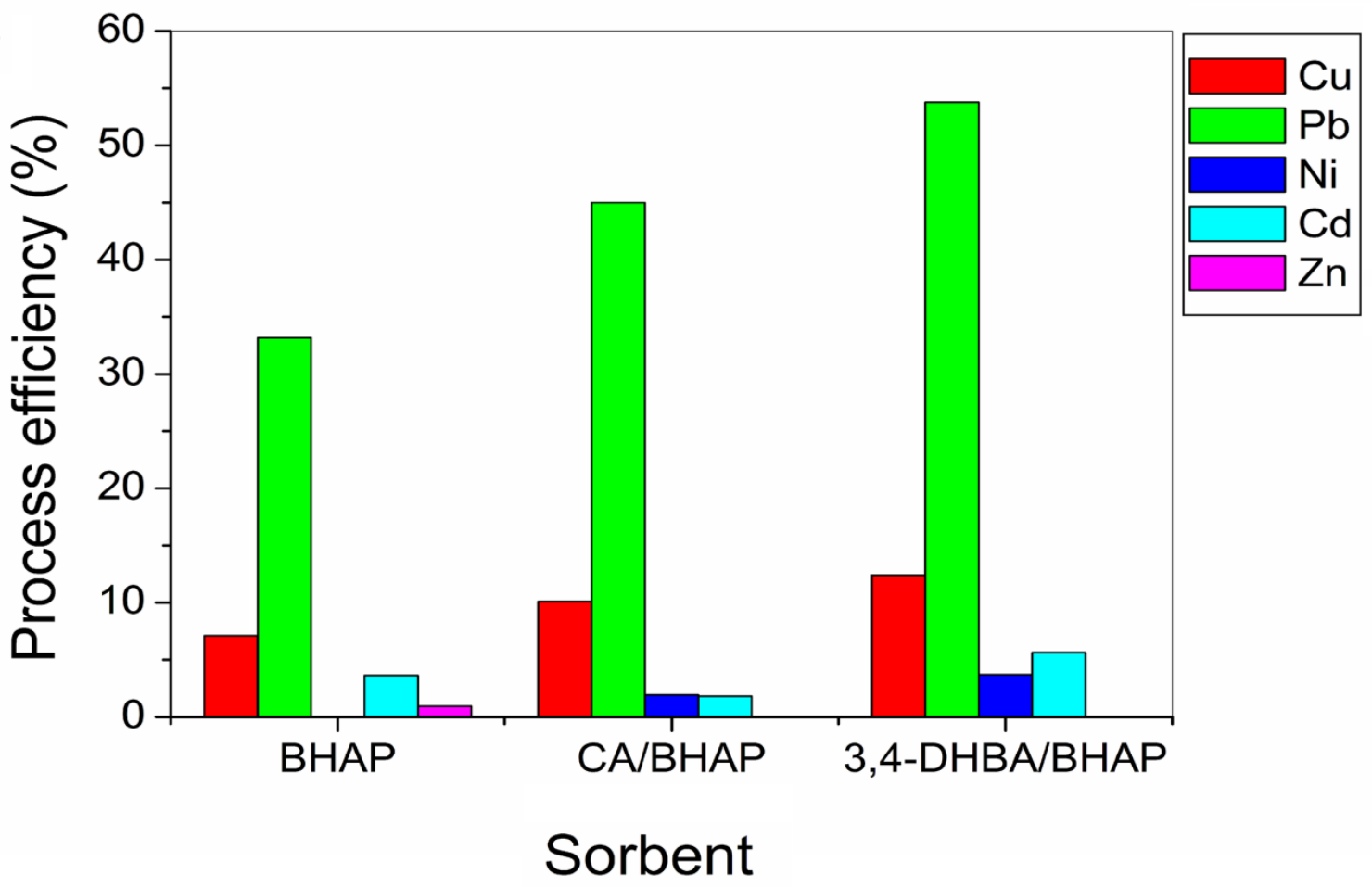

Figure 4. The percentage of sorbed $\mathrm{Cu}, \mathrm{Pb}, \mathrm{Ni}, \mathrm{Cd}$ and $\mathrm{Zn}$ ions from equimolar ion mixtures of total concentration (A) $10^{-3} \mathrm{~mol} / \mathrm{L}$ and (B) $10^{-1} \mathrm{~mol} / \mathrm{L}$, at equilibrium with either BHAP or CA/BHAP or 3,4-DHBA/BHAP powders 

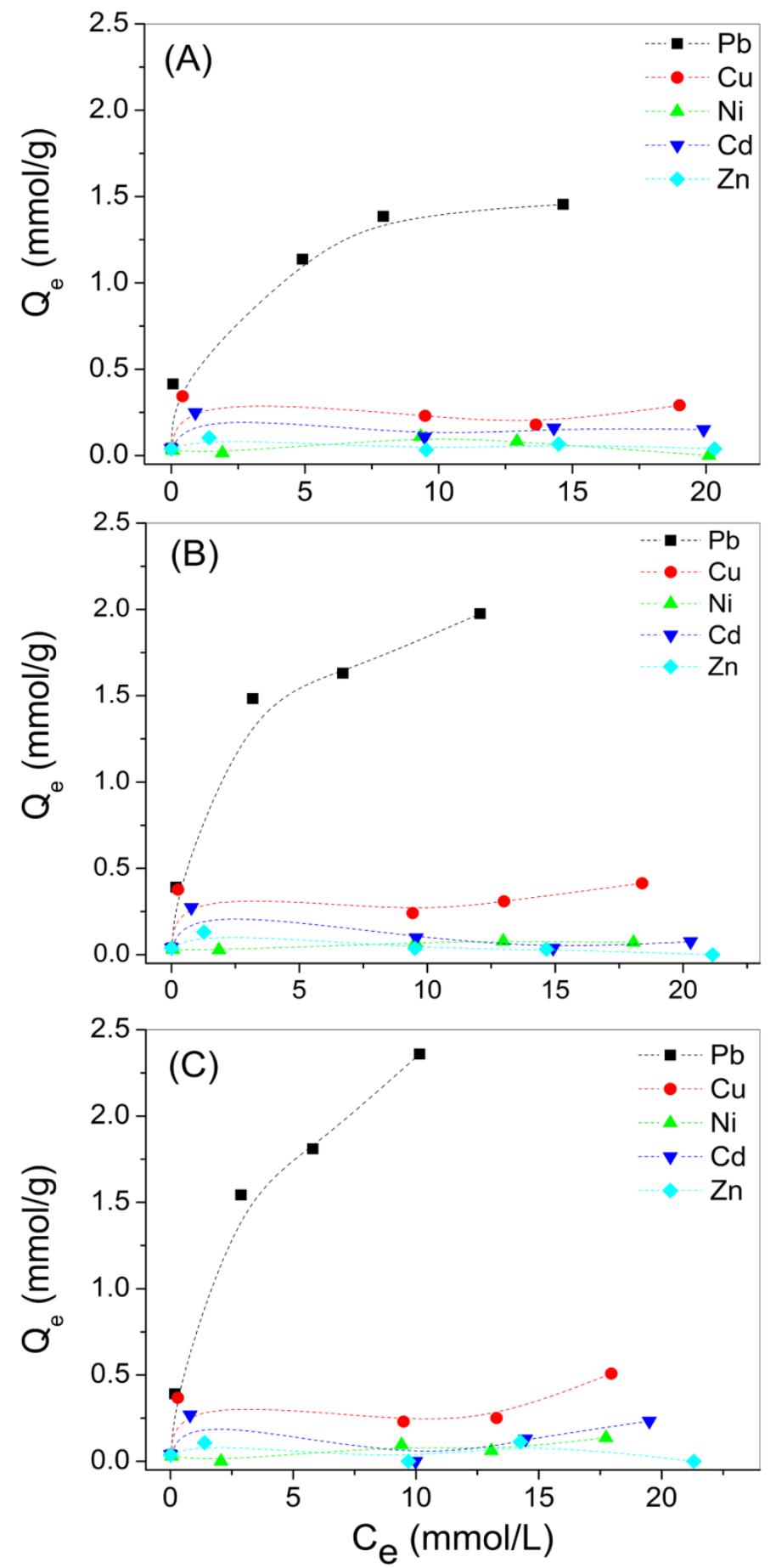

Figure 5. The isotherms of sorption of each component from equimolar five-component solutions ( $\mathrm{Cu}, \mathrm{Pb}, \mathrm{Ni}, \mathrm{Cd}$, and $\mathrm{Zn}$ ions) in various systems: (A) BHAP, (B) CA/BHAP, and (C) 


\section{SUPPORTING INFORMATION}

Figure 1S. The TGA data from as-prepared BHAP (a), CA/BHAP (b), and 3,4-DHBA/BHAP (c) powders obtained in the temperature range $25-1000^{\circ} \mathrm{C}$ at a heating rate of $10{ }^{\circ} \mathrm{C} / \mathrm{min}$, in the dynamic air atmosphere (flow rate $20 \mathrm{~cm}^{3} / \mathrm{min}$ )

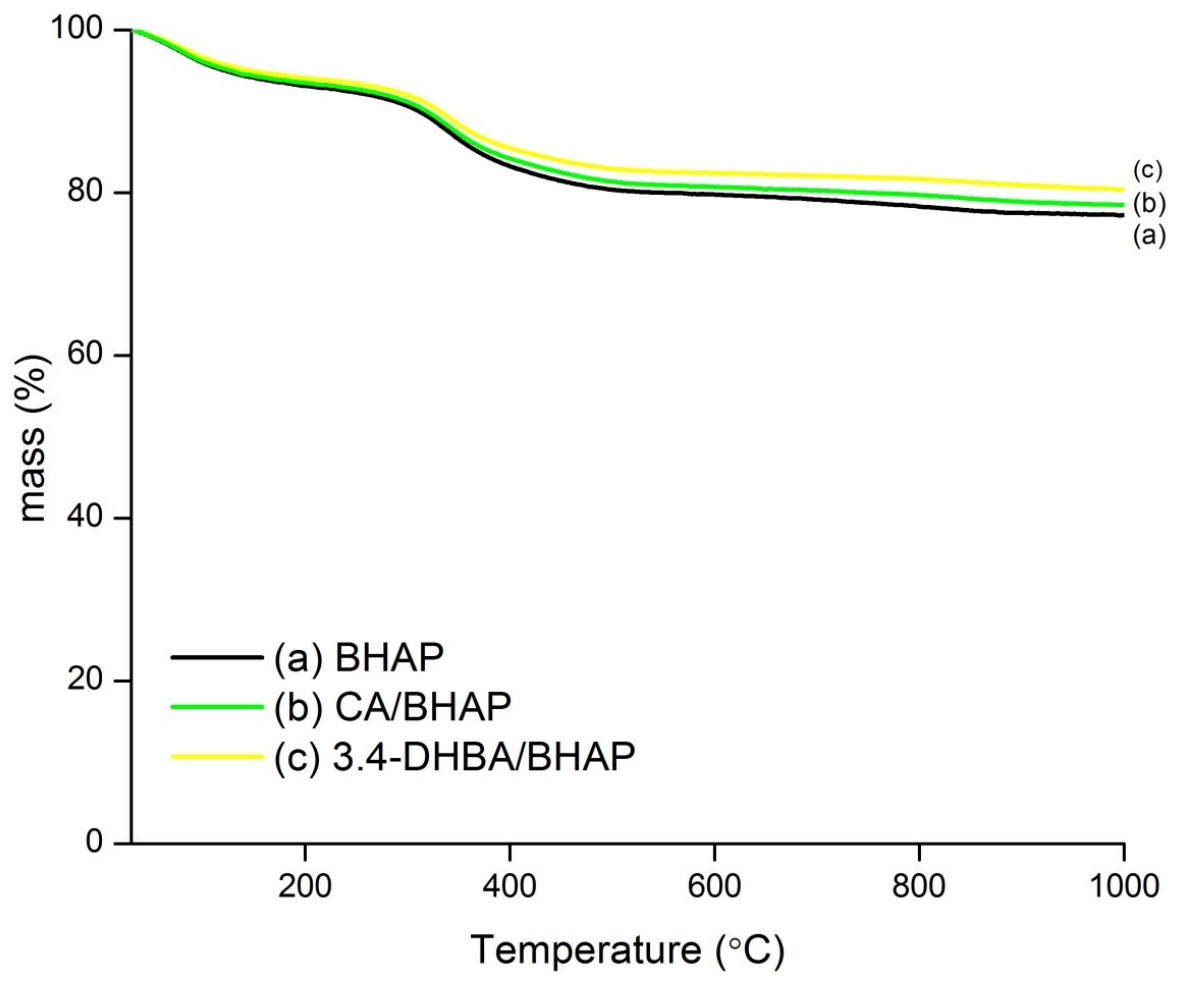


Table S1. Zeta potential of as-prepared BHAP, CA/BHAP, and 3,4-DHBA/BHAP powders dispersed in the inert electrolyte $\left(10^{-2} \mathrm{~mol} / \mathrm{L} \mathrm{KNO}_{3}\right.$, solid-to-solution ratio $\left.1 / 200\right)$.

\begin{tabular}{lcc}
\hline Sample & Equilibrium $\mathrm{pH}$ & Zeta potential $(\mathrm{meV})$ \\
\hline BHAP & $7.5 \pm 0.1$ & $-10.3 \pm 0.6$ \\
CA/BHAP & $7.2 \pm 0.1$ & $-10.5 \pm 1.4$ \\
$3,4-D H B A / B H A P$ & $7.3 \pm 0.1$ & $-12.3 \pm 1.0$ \\
\hline
\end{tabular}


Figure S2. Linear fits of $\mathrm{Pb}$ equilibrium sorption from five-component equimolar mixtures by BHAP, CA/BHAP, and 3,4-DHBA/BHAP using Langmuir (A) and Freundlich (B) isotherm models
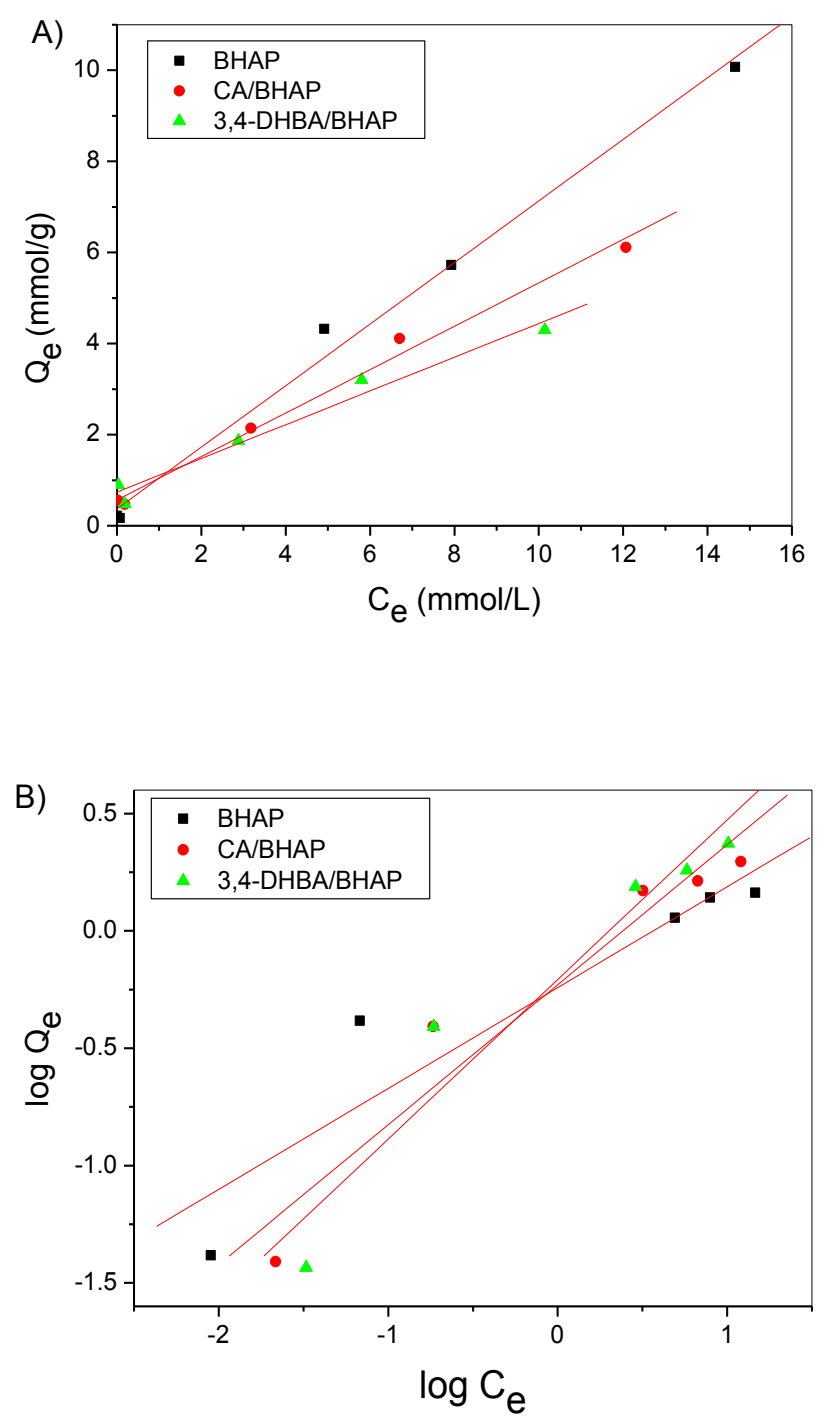